\title{
The Short-Term Impact of the COVID-19 Epidemic on Socio-Economic Activities in China Using OMI- NO2 Monitoring Results
}

\author{
Hongye Cao \\ Chang'an University \\ Ling Han ( $\square$ hanl2019@126.com ) \\ Chang'an University
}

\section{Research Article}

Keywords: remote sensing, OMI, NO2, COVID-19, socio-economic activities

Posted Date: October 7th, 2021

DOl: https://doi.org/10.21203/rs.3.rs-838394/v1

License: (c) (1) This work is licensed under a Creative Commons Attribution 4.0 International License.

Read Full License 


\section{Abstract}

As an air pollutant closely related to urban traffic and heavy industrial capacity, the variation of NO2 (Nitrogen Dioxide) concentration can directly reflect the strength of socio-economic activities. Using the weekly average results of daily product synthesis of tropospheric NO2 column concentrations from OMI satellite inversion, a weekly-scale variation series of standardized socioeconomic activity index during the Spring Festival period of 2019-2021 is constructed. The results show that the Spring Festival holiday also suppresses socioeconomic activity in normal years, but the Coronavirus disease 2019 (COVID-19) epidemic leads to an extended period of 2-3 weeks of weakened socioeconomic activity in China after the holiday, while the minimum value of socioeconomic activity intensity decreases by 0.12 . Although socioeconomic activity is significantly suppressed in the short term, the intensity of socio-economic activity rises steadily with the gradual resumption of work and production everywhere from the third week after the Spring Festival in China and has reached $60.91 \%$ of the highest level before the holiday in the seventh week after the holiday.

\section{Introduction}

The outbreak of Coronavirus disease 2019 (COVID-19) in Wuhan, China, in late December 2019 has spread for nearly two months, with more than 80,000 confirmed cases and 4,000 deaths reported in mainland China as of December 30,2020, causing serious harm to the physical and mental health of the general public in China. At the same time, to block the transmission of the virus to the greatest extent possible, preventive and control measures such as city closure and travel restrictions have been gradually implemented in Wuhan, Hubei Province, China, and other areas affected by the epidemic since January 23,2020 . Since mid to late February 2020 , socio-economic order is being restored in an orderly manner as the epidemic is gradually brought under control. Except for Hubei Province in the core area of the epidemic, the resumption of work and production in the vast majority of provinces is gradually taking place. However, the epidemic is still in the state of external prevention of importation and internal prevention of spread, and it is not feasible to obtain relevant data to evaluate the overall socio-economic impact of the epidemic on China in the short term through a large-scale socioeconomic survey, so it is necessary to explore a feasible monitoring method to quantitatively assess the short-term change process of socioeconomic activities.

Nitrogen dioxide (NO2), as an important pollutant gas, is also one of the six atmospheric pollutants that the environmental protection authorities of various countries are focusing on (Kong et al., 2020; Liu and Du, 2016). NO2 mainly comes from emissions from urban traffic and heavy chemical industries, biomass combustion, soil release, and lightning, among which NO2 in winter is mainly released from anthropogenic activities (van der A et al., 2008). The three most important sources of anthropogenic NOx emissions are industry, transportation, and power plants, contributing $42.0 \%, 35.2 \%$, and $19.2 \%$, respectively, to the total anthropogenic NOx emissions in China in 2017, according to the Chinese multiresolution emission inventory (Zheng et al., 2018). Therefore, changes in industry and transportation may lead to significant changes in NOx emissions. For example, during the Spring Festival (SF) holiday, the 
longest holiday in China (one day before SF to five days after it), many factories will stop production, and therefore NOx emissions from industry will decrease.

Emissions from vehicle exhaust from urban traffic and emissions from energy-intensive heavy industries such as steel and chemical industries, as the main sources of NO2 in the atmosphere, can effectively reflect the changes in socioeconomic activities in China, especially in eastern China. The accuracy of NO2 monitoring results based on ground stations is relatively high, but it is difficult to meet the needs of largescale monitoring and to grasp the spatial and temporal variation patterns of pollutants from a macroscopic perspective (Gao and $\mathrm{Yu}, 2015$ ). Therefore, for analyzing the impact of the epidemic on a national scale, remote sensing-based monitoring methods have obvious advantages.

Since the 1990s, with the increasing concern of humans about the atmospheric environment and the emergence of environmental satellites for earth observation, Global Ozone Monitoring Experiment (GOME), Scanning Imaging Absorption Spectrometer for Atmospheric Chartography (SCIAMACHY), Ozone Monitoring Instrument (OMI), Tropospheric Monitoring Instrument (TROPOMI), and other satellite sensors have been applied to the remote sensing monitoring of NO2 column concentration in the troposphere(Boersma et al., 2014; Bracher et al., 2005; Griffin et al., 2019; Martin et al., 2004; Russell et al., 2011). Because of the advantages of satellite remote sensing data in the analysis of NO2 pollution spatial and temporal variation patterns, the relevant data have been widely applied to environmental pollution monitoring in different regions of China, such as Beijing-Tianjin-Hebei (BTH), Yangtze River Delta (YRD), Pearl River Delta (PRD), and Shandong Province(Heng et al., 2015; Wei et al., 2018; Zheng et al., 2014; Zhou et al., 2015).

In addition to the analysis of NO2 pollution patterns in long time series, relevant studies on the impact of major events on pollutant emissions, such as the parade to commemorate the 70th anniversary of the victory of the War of Resistance and the APEC meeting in 2015, have also appeared (Tao et al., 2009; Zhang et al., 2017a). Also, for related economic issues, studies are analyzing the impact of economic recession on NO2 pollution emissions at the national scale in the United States (Russell et al., 2012). Taken together, the relevant studies show that using NO2 pollution concentration to analyze the shortterm change process of socioeconomic activities during the outbreak has good application prospects.

In the study, based on $\mathrm{OMI}$ (Ozone Monitoring Instrument) satellite remote sensing data by establishing a standardized NO2 emission index, we attempted to analyze the change process of NO2 concentration in 2020, quantified the potential impact of the epidemic on socio-economic activities in China, and explored the feasibility of using pollutant remote sensing monitoring technology to analyze the short-term change process of socio-economic activities at large scales.

\section{Data And Methods}

\subsection{Data and processing}


The primary data used in the study are remote sensing inversion products from the OMI satellite sensor, a hyperspectral atmospheric environmental monitoring sensor carried on board the NASA (National Aeronautics and Space Administration) Earth observation satellite Aura, launched in 2004. The sensor, jointly developed by the Netherlands, Finland, and NASA, contains three channels, UV-1, UV-2, and VIS, with an amplitude of $2,600 \mathrm{~km}$ and can cover the globe once a day(Anoruo, 2020). The main monitoring targets of $\mathrm{OMI}$ are a variety of trace gases including $\mathrm{O} 3, \mathrm{NO} 2, \mathrm{SO} 2, \mathrm{CH} 2 \mathrm{O}$, etc. The tropospheric column concentration products of $\mathrm{OMI}$ that can effectively reflect the NO2 pollution emission characteristics are mainly based on spectral information in the visible wavelength range of $405 \sim 465 \mathrm{~nm}$, obtained by Differential Optical Absorption Spectroscopy (DOAS) inversion. In this study, we use the OMI Level 3 product OMNO2d from the official NASA (National Aeronautics and Space Administration) website, which is stored in HDF-EOS5 format, and the file contains tropospheric NO2 column concentration (TropNO2) and total NO2 column concentration (TotNO2) data with a spatial resolution of $0.25^{\circ} \times 0.25^{\circ}$ and uncertainty of about $15 \%$ in the product(Zhang et al., 2017b).

To de-minimize, the influence of clouds on the monitoring results, Cloud-Screened daily products of TropNO2 were used in the analysis. Since there is a serious data deficit in the daily NO2 data of OMNO2d, in order to obtain relatively effective monitoring results, weekly-scale monitoring products are established by mean synthesis of daily products every 7 days. Considering that the SF holiday also has a large impact on socio-economic activities, in order to objectively analyze the short-term impact process of the epidemic, the weekly average TropNO2 products for the three SF seasons (7 weeks before to 8 weeks after the SF) during 2019-2021 were analyzed.

The industrial thermal anomaly and radiation intensity data were obtained from the daily product dataset of $375 \mathrm{~m}$ resolution multispectral data from the VIIRS sensor carried by the Soumi-NPP satellite. In this study, the thermal anomalies falling on industrial land were extracted by combining land use classification data and excluding the interference of factors such as reflected sunlight from buildings.

\subsection{Methods}

\subsubsection{Standardized socio-economic activity index}

In order to quantitatively analyze the changes in the intensity of socio-economic activities in a specific region, a standardized socio-economic activity index (SSEI) on a weekly scale is established using the highest pre-holiday weekly average concentration in the region in that year as a reference, with the following equation: 


$$
\operatorname{SSEI} I_{m n k}=\frac{N_{m n k}}{\operatorname{Max}\left(N_{m n k}\right)}
$$

Where $S S E I_{\text {mak }}$ is the standardized socioeconomic activity index for the $\mathrm{n}$-th week of the m-th region in the k-th year, $N_{m m i}$ is the mean TropNO2 value for the n-th week of the m-th region in the k-th year, $\operatorname{Max}\left(N_{m m i k}\right)$ is the maximum value of TropNO2 in the $\mathrm{n}$-th week of the $\mathrm{m}$-th region in the $\mathrm{k}$-th year。

\subsubsection{Kernel density estimation}

Kernel density estimation (KDE) is used to calculate the unit density of point and line element measurements in a specified neighborhood, which can visualize the distribution of discrete measurements in a continuous region (Jiang et al., 2017), and the raster value is the unit density. If there exist thermal anomalies $x_{1}, x_{2}, \ldots, x_{n}$, then the kernel density at any thermal anomaly aggregation area $x_{i}$ is estimated as:

$$
f(x)=\frac{1}{n h} \sum_{i=1}^{n} K\left(\frac{x-x_{i}}{h}\right) \xi_{i}(k)
$$

Where $K$ is the weight function (Gaussian function is used in this paper), $h$ is the search radius, and $x-x_{i}$ denotes the distance from the estimated point to the sample $x_{i}$.

In this paper, the kernel density of thermal anomalies is estimated based on their spatial distribution and the magnitude of radiation intensity to reflect the scale of industrial production in each region.

\section{Results And Discussion}

\subsection{Characteristics of TropNO2 column concentrations in China during the SF season in the last three years}

By comparing the course of weekly mean TropNO2 column concentrations in China during the last three SF seasons (Fig. 1), it can be seen that all three SF seasons show a trend of gradual decrease before the festival and gradual increase after the festival. The highest weekly value in 2019 was $6.22 \times 10^{15} \mathrm{molecules} / \mathrm{cm}^{2}$ in the 5 th week before the SF; the highest value in 2020 was $5.30 \times 10^{15}$ molecules $/ \mathrm{cm}^{2}$ in the 7th week before the SF; the highest weekly value in 2021 was $5.87 \times 10^{15}$ molecules $/ \mathrm{cm}^{2}$ in the 7 th week before the SF. The lowest NO2 column concentrations in the three years of the SF season occurred in the first week after the SF in 2019. NO2 pollution takes time to dilute, transform, and settle after formation, so the lowest NO2 values often lag slightly behind the 
pollutant reduction process(Zhang et al., 2017a). In contrast to 2019, the lowest value in 2020 occurs in the second week after the SF. In terms of the minimum values of weekly concentrations during the SF season, the weekly minimum value of the SF season in $2020\left(1.72 \times 10^{15}\right.$ molecules $\left./ \mathrm{cm}^{2}\right)$ is $1.19 \times 10^{15}$ molecules $/ \mathrm{cm}^{2}$ lower than the weekly minimum value of the same period in 2019 $\left(2.91 \times 10^{15}\right.$ molecules $\left./ \mathrm{cm}^{2}\right)$, and the extended process of pollutant concentration reduction and the concentration. The reduced minimum should be directly related to the impact caused by the COVID-19 outbreak. The weekly minimum for the SF season in $2021\left(2.80 \times 10^{15} \mathrm{molecules} / \mathrm{cm}^{2}\right)$ is $1.09 \times 10^{15}$ molecules $/ \mathrm{cm}^{2}$ higher than the weekly minimum for the same period in 2020 .

Figs 2-4 show the weekly variation process of TropNO2 column concentration before the SF (from Dec 2nd, 2019 to Jan 19th, 2020), NO2 distribution during the SF week (from Jan 20th to Feb 2nd, 2020), and weekly variation process after the SF (from Feb 3rd to Mar 29th, 2020), respectively. In general, before and during the SF week, the national high concentration of NO2 range a lot, and show a gradually decreasing law; after the SF, the national high concentration of NO2 is less, especially the first and second week after the SF NO2 concentration is the smallest, and from the third week after the SF shows a gradually increasing law. In addition, from its spatial distribution pattern, its main high-value distribution areas coincide with the hotspot areas of socio-economic development, in which BTH, YRD, and PRD areas all show high-value areas of NO2 pollution.

\subsection{Temporal variation of industrial thermal anomalies under the influence of epidemics}

The number of industrial thermal anomalies can indicate the spatial distribution of industrial production as well as the various characteristics, and the magnitude of radiation intensity can characterize the scale of industrial production and energy consumption, which indirectly reflects the air quality condition (Sun et al., 2020; Sun et al., 2019). Figure 6 shows the distribution of industrial thermal anomalies and the change of kernel density of radiation intensity in the BTH in the SF season in 2020. In general, it seems that the thermal anomalies are mostly distributed in three heavy industrial cities, Tangshan, Tianjin, and Handan in China. Comparing the temporal changes of thermal anomalies before and after the SF in the three regions, it is easy to find that the number of thermal anomalies in the YRD stays at 50 before the SF, decreases gradually from the first week before the SF until the second week after the SF, and then the thermal anomalies increase substantially; the thermal anomalies in the BTH region decrease gradually from the seventh week to the third week before the SF. In the following three weeks, the number of thermal anomalies remained around 50 . The number of thermal anomalies increases substantially from the SF week; unlike the other two regions, the number of thermal anomalies in the PRD region is always maintained at a low level during the SF season. Comparing the radiation intensity of thermal anomalies in the three regions (Table 1), the radiation intensity of the BTH region before and after the SF is always maintained around $1.6 \mathrm{MW}$; the radiation intensity of the PRD region gradually decreases from the seventh week before the Spring Festival, reaches the lowest value in the first week after the SF, and then rises rapidly; the radiation intensity of the YRD region gradually decreases from the second week before 
the SF until it reaches the lowest point in the Spring Festival week, and then starts to rise gradually. Due to the heavy industrial structure in the BTH region, which is dominated by heavy industries with high pollution and high energy consumption such as thermal power generation, iron and steel, and cement, such industries did not stop production during the epidemic because of the existence of uninterruptible production processes(Xia et al., 2018). The results of this study also verified the findings.

Table 1

Thermal anomalies (TA) and radiation intensities (FPR, Unit: MW) in the BTH, YRD, and PRD regions.

\begin{tabular}{lllllll}
$\begin{array}{l}\text { Weeks relative to } \\
\text { the SF }\end{array}$ & $\begin{array}{l}\text { TA of the } \\
\text { BTH }\end{array}$ & $\begin{array}{l}\text { FRP of the } \\
\text { BTH }\end{array}$ & $\begin{array}{l}\text { TA of the } \\
\text { PRD }\end{array}$ & $\begin{array}{l}\text { FPR of the } \\
\text { PRD }\end{array}$ & $\begin{array}{l}\text { TA of the } \\
\text { YRD }\end{array}$ & $\begin{array}{l}\text { FPR of the } \\
\text { YRD }\end{array}$ \\
\hline-7 & 131 & 1.65 & 37 & 3.13 & 45 & 3.51 \\
\hline-6 & 146 & 1.46 & 35 & 1.92 & 52 & 3.31 \\
\hline-5 & 74 & 1.65 & 3 & 0.61 & 38 & 3.40 \\
\hline-4 & 81 & 1.70 & 17 & 2.14 & 50 & 3.73 \\
\hline-3 & 56 & 1.71 & 17 & 1.61 & 55 & 3.54 \\
\hline-2 & 56 & 1.60 & 22 & 1.49 & 29 & 3.68 \\
\hline-1 & 55 & 1.77 & 1 & 1.19 & 72 & 3.14 \\
\hline 0 & 65 & 1.79 & 23 & 0.81 & 67 & 2.48 \\
\hline 1 & 91 & 1.65 & 0 & 0.65 & 53 & 3.01 \\
\hline 2 & 141 & 1.62 & 4 & 1.66 & 45 & 2.97 \\
\hline 3 & 222 & 1.83 & 8 & 1.61 & 151 & 3.94 \\
\hline 4 & 80 & 1.20 & 7 & 0.90 & 100 & 4.39 \\
\hline 5 & 146 & 1.70 & 2 & 1.60 & 113 & 4.12 \\
\hline 6 & 327 & 1.64 & 8 & 1.94 & 130 & 4.53 \\
\hline 7 & 431 & 1.77 & 5 & 2.75 & 215 & 3.89 \\
\hline 8 & 264 & 1.58 & 6 & 2.01 & 60 & 3.99 \\
\hline
\end{tabular}

\subsection{Time-series changes of SSEI under the influence of the epidemic}

Calculating SSEI according to Eq. 1, it can be seen that the SSEI reached its highest value in the 5th week before the SF season in 2019 , rapidly decreased to bottom in the 1 st week after the SF, and rapidly recovered to $66.8 \%$ of the highest value in the 3rd week after the SF, and then kept fluctuating and changing around $70 \%$ due to short-term meteorological processes (Fig. 6). The lowest value of the SSEI 
was only 0.32 in 2020 due to the epidemic, which is lower than 0.15 lower than that of 2019, and the lowering period lasted longer. The SSEl starts to recover gradually in the 4th week after the SF in 2020 and reaches the highest value of 0.61 in the 8th week after the SF, which is only 0.12 different from the value of the index in the same week of the SF season in 2019, so it can be seen that although the epidemic has had a serious impact on socio-economic activities nationwide, the SSEl rises week by week from the 4th week onwards as the effectiveness of epidemic prevention gradually emerges, indicating that socio-economic activities are steadily recovering. The SSEI decreases to the lowest value in the second week before the SF season in 2021 and then remains around 0.5 until the third week after the SF, and gradually increases from the fourth week after the SF until it reaches the highest value in the eighth week.

To grasp the short-term impact process of the epidemic on the economic hotspot regions in China, the change process of the SSEl of the three major urban clusters (BTH, YRD, and PRD) in the SF season of 2020 was analyzed (see Fig. 7). The SSEI of the PRD region decreases most significantly in the previous period due to the epidemic, with the SSEI dropping sharply to $18.4 \%$ of the highest value, while the YRD and $\mathrm{BTH}$ regions also drop to $22.8 \%$ and $31.9 \%$ of the highest value, respectively. The PRD region has the largest decrease, which may be directly related to its highest reliance on foreign workers. A series of preventive measures such as "city closure" and traffic restrictions have significantly pushed back the wave of returning workers, with limited recovery in the PRD region in the first few weeks after the holiday. However, as the main heavy chemical base in the three major urban clusters, the pillar industries of the BTH region, such as iron and steel metallurgy and petrochemicals, are resource-based industries with high pollution and energy consumption, which require high continuity of factory production, and thus the SSEl drop is the smallest(Bo et al., 2017; Le et al., 2019; Zhao et al., 2021). The drop process of the SSEI in the BTH region is similar to that of the national average, reaching the lowest after the 3rd week after the SF, while the drop process in the YRD region The decline process in the YRD region continued until the 4th week after the SF. Due to the lack of data for two weeks, it is not possible to know the recovery of socioeconomic activity in the PRD regions at that time, but from the overall trend, the overall recovery in economically developed regions is slightly better than the national average. The situation is slightly better than the national average.

\section{Conclusion}

Based on the weekly synthesis results of tropospheric NO2 column concentrations from OMI satellite inversions, the SSEI differences for the 2019-2021 SF season were compared by constructing SSEI, and it was found that the COVID-19 epidemic caused some significant effects on socio-economic activities in China in the short term. For example, 1) the epidemic prolonged the period of reduced socioeconomic activity after the SF holiday by $2-3$ weeks; 2 ) the epidemic caused the lowest value of SSEI to decrease by 0.12 relative to a normal year; 3 ) the SSEI in China steadily rebounded from the third week after the SF and recovered to $61.1 \%$ of the highest value before the SF in the eighth week after the SF, and economic hotspots such as the BTH and YRD also showed similar trends. 
Since conventional research methods are difficult to obtain information on the changes of socioeconomic activities on a large scale in a short period, it is impossible to assess the scope and extent of the socioeconomic impact of the epidemic. provide a new quantitative analysis method, which reflects the short-term suppression and recovery process of socio-economic activities in China by the epidemic and the SF holidays. Of course, due to the differences in the industrial structure of different regions, the index can only analyze the time-series change process for the same region, and the differences in the proportion of heavy chemical industries in different regions have some influence on the results. In addition, although the overall precipitation in China during the SF season is limited, the widespread rain and snow processes still cause the problem of insufficient effective monitoring results. At the same time, the method is mainly suitable for large-scale analysis because the atmospheric pollutants may move with atmospheric activities in a small area during the monitoring period.

\section{Declarations}

\section{Ethics approval and consent to participate}

Not applicable.

\section{Consent for publication}

All authors agree to have this manuscript published in this journal.

\section{Declaration of Competing Interest}

The authors declare that they have no competing interests.

\section{Author contribution}

Hongye Cao is responsible for the conceptualization, methodology, software, validation, and visualization of this article, while Ling Han is responsible for funding acquisition and supervision.

\section{Data Availability}

Data sharing is not applicable to this article as no datasets were generated or analyzed during the current study.

\section{Acknowledgements}

The authors would like to acknowledge the National Aeronautics and Space Administration for providing the OMI data, industrial thermal anomaly and radiation intensity data. We're also thankful for several anonymous reviewers for their help in improving this paper with their constructive suggestions.

\section{References}


1. Anoruo, C.M., 2020. Validation of OMI seasonal and spatio-temporal variations in aerosol-cloud interactions over Banizoumbou using AERONET data. Journal of Atmospheric and Solar-Terrestrial Physics 211, 105457.

2. Bo, X., Xu, J., Du, X.H., Guo, Q.Q., Zhen, R.Q., Tian, J., Cai, B.F., Wang, L.F., Ma, F.S., Zhou, B.H., 2017. Impacts assessment of steel plants on air quality over Beijing-Tianjin-Hebei area. China Environ. Sci. 37, 1684-1692.

3. Boersma, K., Jacob, D., Trainic, M., Rudich, Y., De Smedt, I., R, D., Eskes, H., 2014. Validation of urban NO2 concentrations and their diurnal and seasonal variations observed from space (SCIAMACHY and OMI sensors) using in situ measurements in Israeli cities. Atmospheric Chemistry and Physics 9 , 3867-3879.

4. Bracher, A., Bovensmann, H., Bramstedt, K., Burrows, J., Clarmann, T., Eichmann, K.-U., Fischer, H., Funke, B., Gil-Lopez, S., Glatthor, N., Grabowski, U., Höpfner, M., Kaufmann, M., Kellmann, S., Kiefer, M., Koukouli, M., Linden, A., López-Puertas, M., Mengistu Tsidu, G., Wuttke, M., 2005. Cross comparisons of 03 and NO2 measured by the atmospheric ENVISAT instruments GOMOS, MIPAS, and SCIAMACHY. Adv. Space. Res. 36, 855-867.

5. Gao, Q., Yu, C., 2015. A review of urbanization impact on nitrogen cycle Progress in Geography 34, 726-738.

6. Griffın, D., Zhao, X.Y., McLinden, C.A., Boersma, F., Bourassa, A., Dammers, E., Degenstein, D., Eskes, H., Fehr, L., Fioletov, V., Hayden, K., Kharol, S.K., Li, S.-M., Makar, P., Martin, R.V., Mihele, C., Mittermeier, R.L., Krotkov, N., Sneep, M., Lamsal, L.N., Linden, M.t., Geffen, J.v., Veefkind, P., Wolde, M., 2019. HighResolution Mapping of Nitrogen Dioxide With TROPOMl: First Results and Validation Over the Canadian Oil Sands. Geophys. Res. Lett. 46, 1049-1060.

7. Heng, L.Z., Ren, S.J., Jia, F.S., Dui, W., Zhong, R.M., Jian, Z., 2015. Variation characteristics and influencing factors of air pollution in Pearl River Delta area from 2006 to 2012. China Environ. Sci. 35, 329-336.

8. Jiang, S.R., Wang, Y., Wang, M., Shi, L., Ma, Z., Lu, G.F., 2017. Industrial sectors and pollution in China based on the regional perspective. China Environ. Sci. 37, 4380-4387.

9. Kong, L., Tang, X., Zhu, J., Wang, Z., Fu, J.S., Wang, X., Itahashi, S., Yamaji, K., Nagashima, T., Lee, H.J., Kim, C.H., Lin, C.Y., Chen, L., Zhang, M., Tao, Z., Li, J., Kajino, M., Liao, H., Wang, Z., Sudo, K., Wang, Y., Pan, Y., Tang, G., Li, M., Wu, Q., Ge, B., Carmichael, G.R., 2020. Evaluation and uncertainty investigation of the NO2, $\mathrm{CO}$ and $\mathrm{NH} 3$ modeling over China under the framework of MICS-Asia III. Atmos. Chem. Phys. 20, 181-202.

10. Le, P., Zhao, Y.Y., Zhao, J.L., Gao, G.L., Ding, G.D., 2019. Spatiotemporal patterns of air pollution in air pollution transmission channel of Beijing-Tianjin-Hebei from 2000 to 2015. China Environ. Sci. 39, 449-458.

11. Liu, H.J., Du, G.J., 2016. Spatial Pattern and Distributional Dynamics of Urban Air Pollution in China An Empirical Study Based on Aqi and Six Sub-Pollutants of 161 Cities. Econ. Geogr. 36, 33-38. 
12. Martin, R.V., Parrish, D.D., Ryerson, T.B., Nicks Jr., D.K., Chance, K., Kurosu, T.P., Jacob, D.J., Sturges, E.D., Fried, A., Wert, B.P., 2004. Evaluation of GOME satellite measurements of tropospheric NO2 and $\mathrm{HCHO}$ using regional data from aircraft campaigns in the southeastern United States. J. Geophys. Res. Atmos. 109, D24307.

13. Russell, A., Perring, A., Valin, L., Bucsela, E., Browne, E., Min, K.-E., Wooldridge, P., Cohen, R., 2011. A high spatial resolution retrieval of NO2 column densities from OMI: method and evaluation. Atmospheric Chemistry and Physics Discussions 11, 12411-12440.

14. Russell, A., Valin, L., Cohen, R., 2012. Trends in OMI NO2 observations over the United States: Effects of emission control technology and the economic recession. Atmospheric Chemistry \& Physics 12 , 12197-12209.

15. Sun, S., Li, L.J., Wu, Z.H., Gautam, A., Li, J.X., Zhao, W.J., 2020. Variation of industrial air pollution emissions based on VIIRS thermal anomaly data. Atmospheric Research 244, 105021.

16. Sun, S., Li, L.J., Zhao, W.J., Wang, L.L., Qiu, Y., Jiang, L., Zhang, L.K., 2019. Industrial pollution emissions based on thermal anomaly remote sensing monitoring: A case study of Southern Hebei urban agglomerations, China. China Environ. Sci. 39, 3120-3129.

17. Tao, J.H., Wang, Z.F., Han, D., Li, S.S., Su, L., Chen, L.F., 2009. Analysis of crop residue burning and tropospheric NO2 vertical column density retrieved from satellite remote sensing in North China. China Environ. Sci. 29, 1016-1020.

18. van der A, R.J., Eskes, H.J., Boersma, K.F., van Noije, T.P.C., Van Roozendael, M., De Smedt, I., Peters, D.H.M.U., Meijer, E.W., 2008. Trends, seasonal variability and dominant NOx source derived from a ten year record of NO2 measured from space. J. Geophys. Res. Atmos. 113, D04302.

19. Wei, Y.Y., Yang, S.Q., Chen, Z.Q., Wang, C.X., Lin, T.S., 2018. Tropospheric NO2 Characteristics of the Yangtze River Delta Region Based on OMI Satellite Data. Environ. Sci. Technol. 41, 80-87.

20. Xia, H.P., Chen, Y.H., Quan, J.L., 2018. A simple method based on the thermal anomaly index to detect industrial heat sources. Int. J. Appl. Earth Obs. Geoinf. 73, 627-637.

21. Zhang, H., Yu, C., Su, L., Jun, L.L., Fan, M., Wang, Y.P., Chen, L.F., 2017a. Emission control effects observed from space during the military parade 2015 in Beijing. J. Remote Sens. 21, 622-632.

22. Zhang, X.Y., Lu, X.H., Liu, L., Chen, D.M., Zhang, X.M., Liu, X.J., Zhang, Y., 2017b. Dry deposition of NO2 over China inferred from OMI columnar NO2 and atmospheric chemistry transport model. Atmos. Environ. 169, 238-249.

23. Zhao, X., Shen, N.C., Li, L.J., Wu, G.F., Tao, J., Zhao, W.J., 2021. Analysis of Changes and Factors Influencing Air Pollutants in the Beijing-Tianjin-Hebei Region During the COVID-19 Pandemic. Environmental Science 42, 1205-1214.

24. Zheng, B., Tong, D., Li, M., Liu, F., Hong, C.P., Geng, G.N., Li, H.Y., Li, X., Peng, L.Q., Qi, J., Yan, L., Zhang, Y.X., Zhao, H.Y., Zheng, Y.X., He, K.B., Zhang, Q., 2018. Trends in China's anthropogenic emissions since 2010 as the consequence of clean air actions. Atmospheric Chemistry and Physics Discussions 18, 14095-14111. 
25. Zheng, X.X., Li, L.J., Zhao, W.J., Zhao, W.H., 2014. Spatial and Temporal Characteristics of Atmospheric NO2 in the Beijing-Tianjin-Hebei Region. Ecology and Environment Sciences, 19381945.

26. Zhou, C.Y., Li, Q., He, Y.X., Wang, Z.T., Chen, H., Zhang, L.J., Mao, H.Q., Yu, C., 2015. Spatial-temporal change of tropospheric NO2 column density and its impact factors over Shandong province during 2005囚2014. China Environ. Sci. 35, 2281-2290.

\section{Figures}

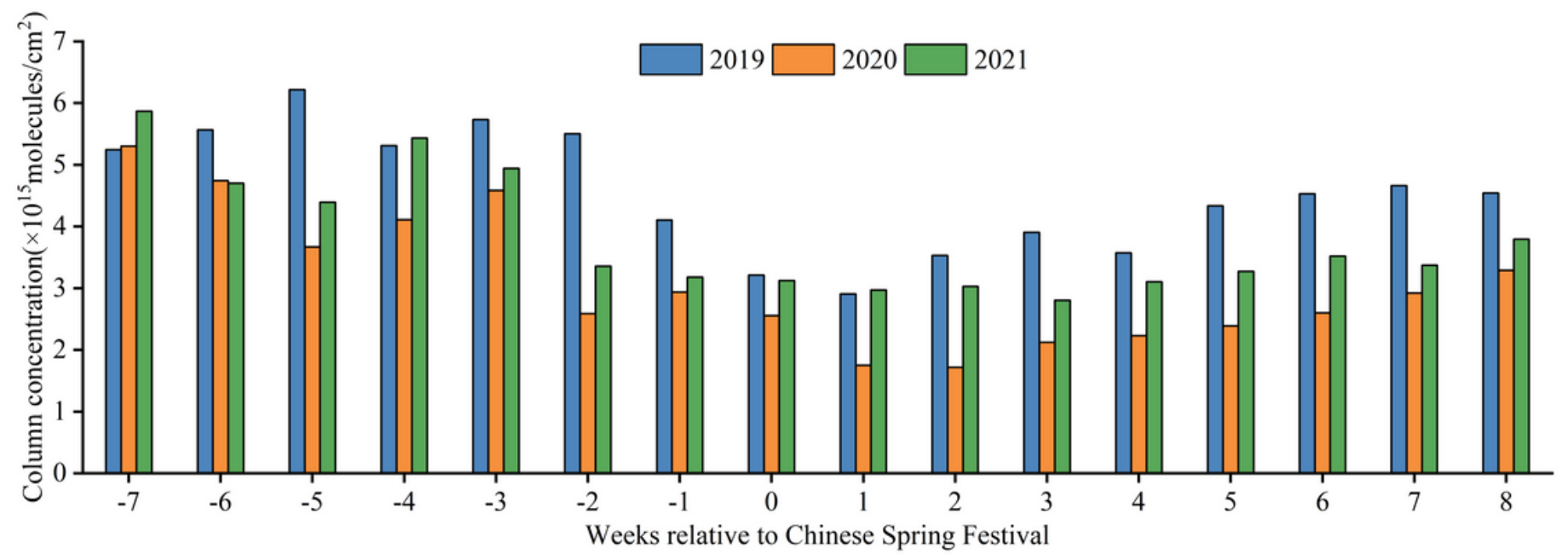

Figure 1

Weekly variation of average tropospheric column NO2 density of China during the recent three Chinese Spring Festival periods. 


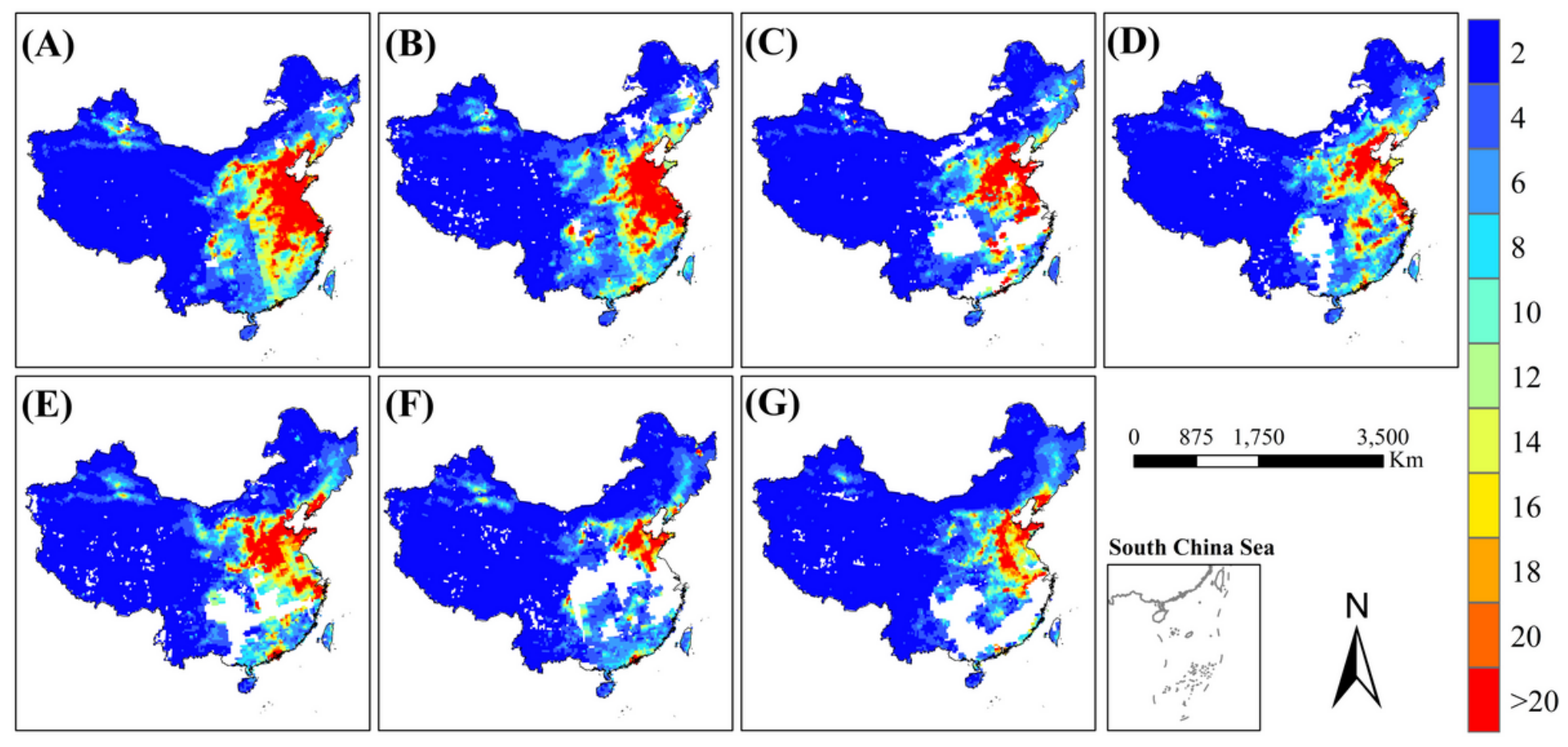

Figure 2

Decreased weekly tropospheric NO2 column density in China from Dec 2th, 2019 to Jan 19th, 2020. 


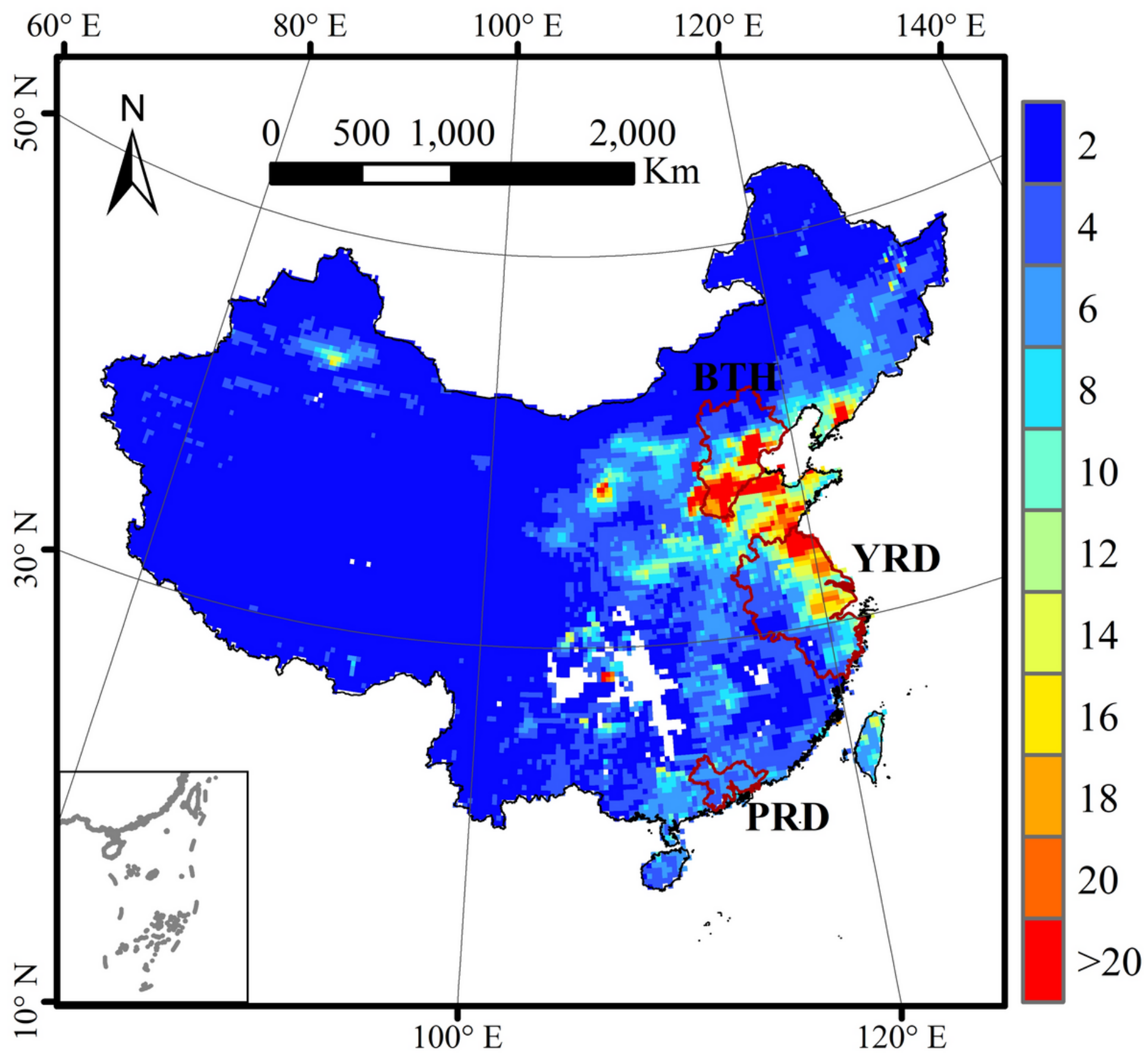

Figure 3

Variation of tropospheric NO2 column concentration in China during the Spring Festival from Jan 20 to Feb 2, 2020. BTH, YRD and PRD denote the Beijing-Tianjin-Hebei, Yangtze River Delta and Pearl River Delta regions in China, respectively. 


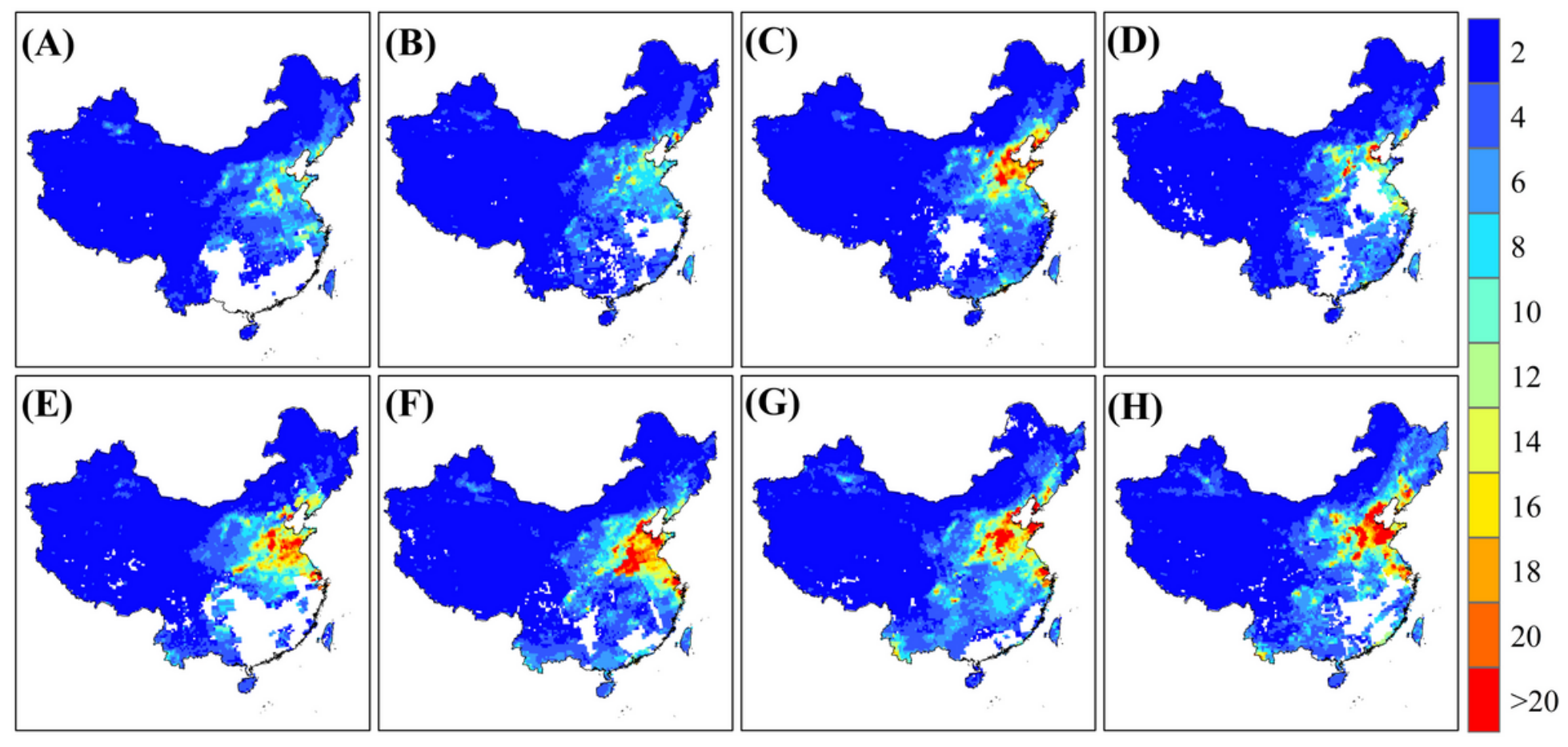

Figure 4

Weekly variation of tropospheric NO2 column concentration in China from Feb 3 to Mar 29, 2020. 

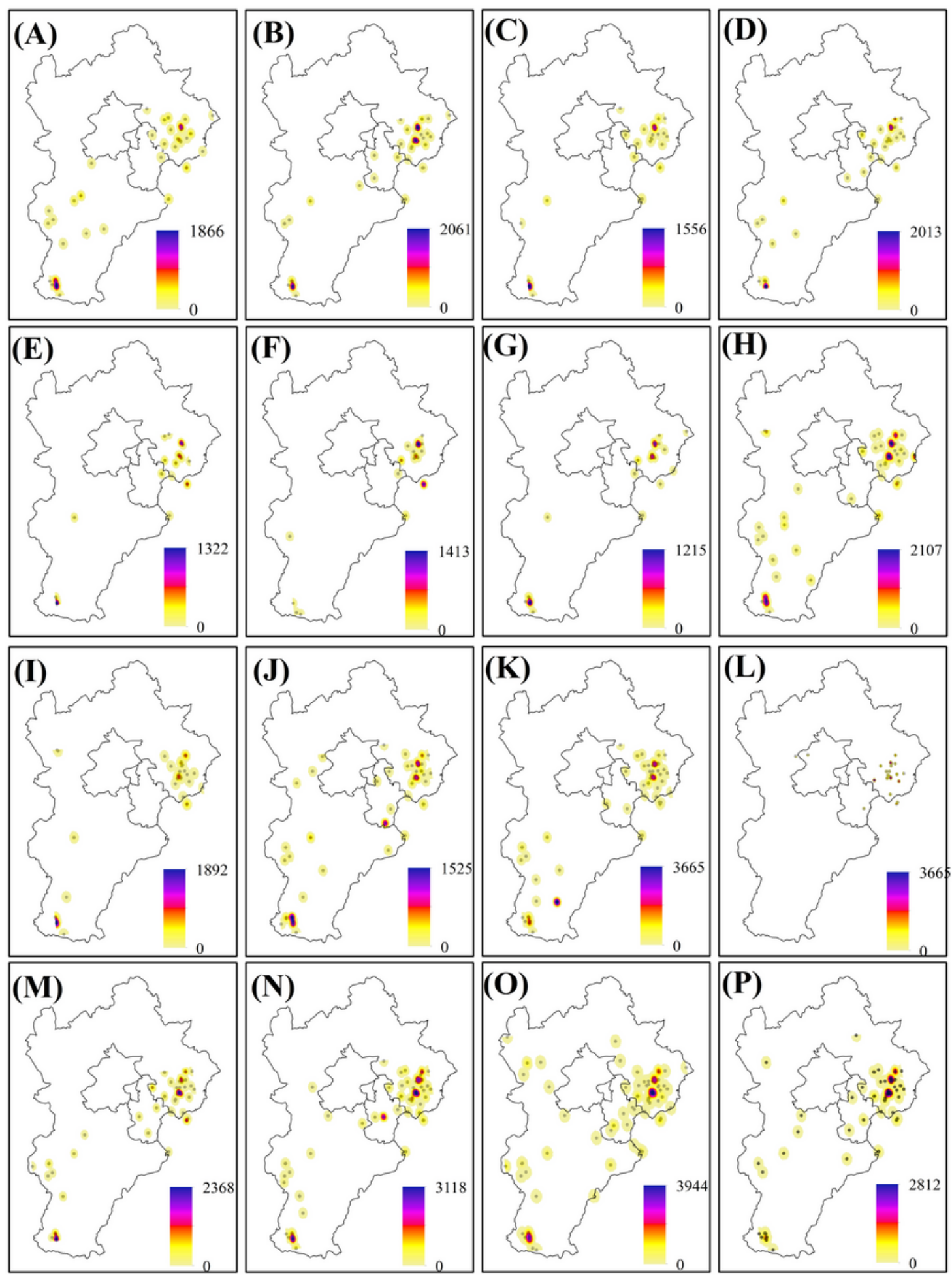

\section{Figure 5}

Kernel density of industrial thermal anomaly and radiation intensity in the BTH region. 


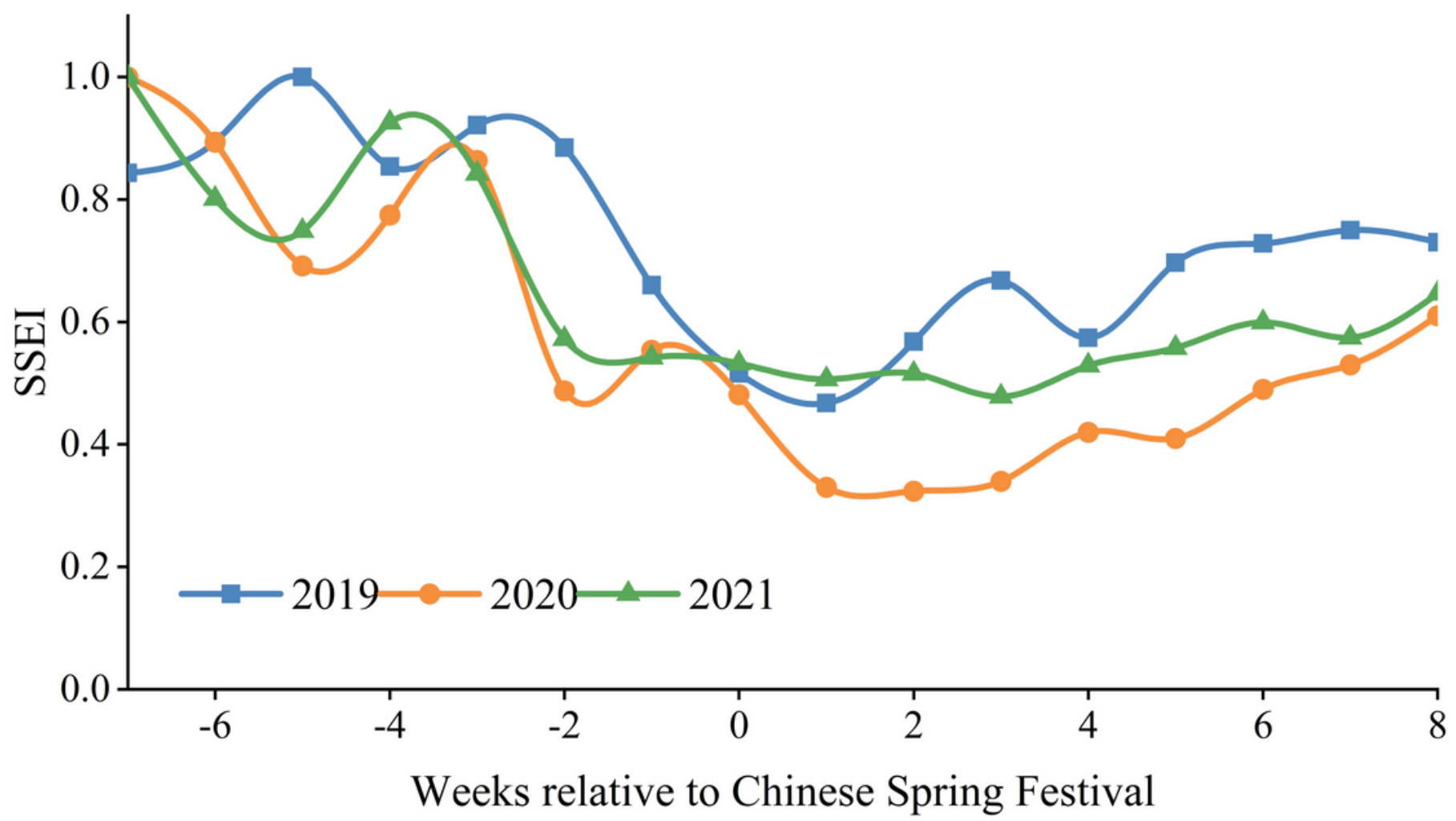

Figure 6

Weekly variation of the SSIE in China during the recent three SF periods.

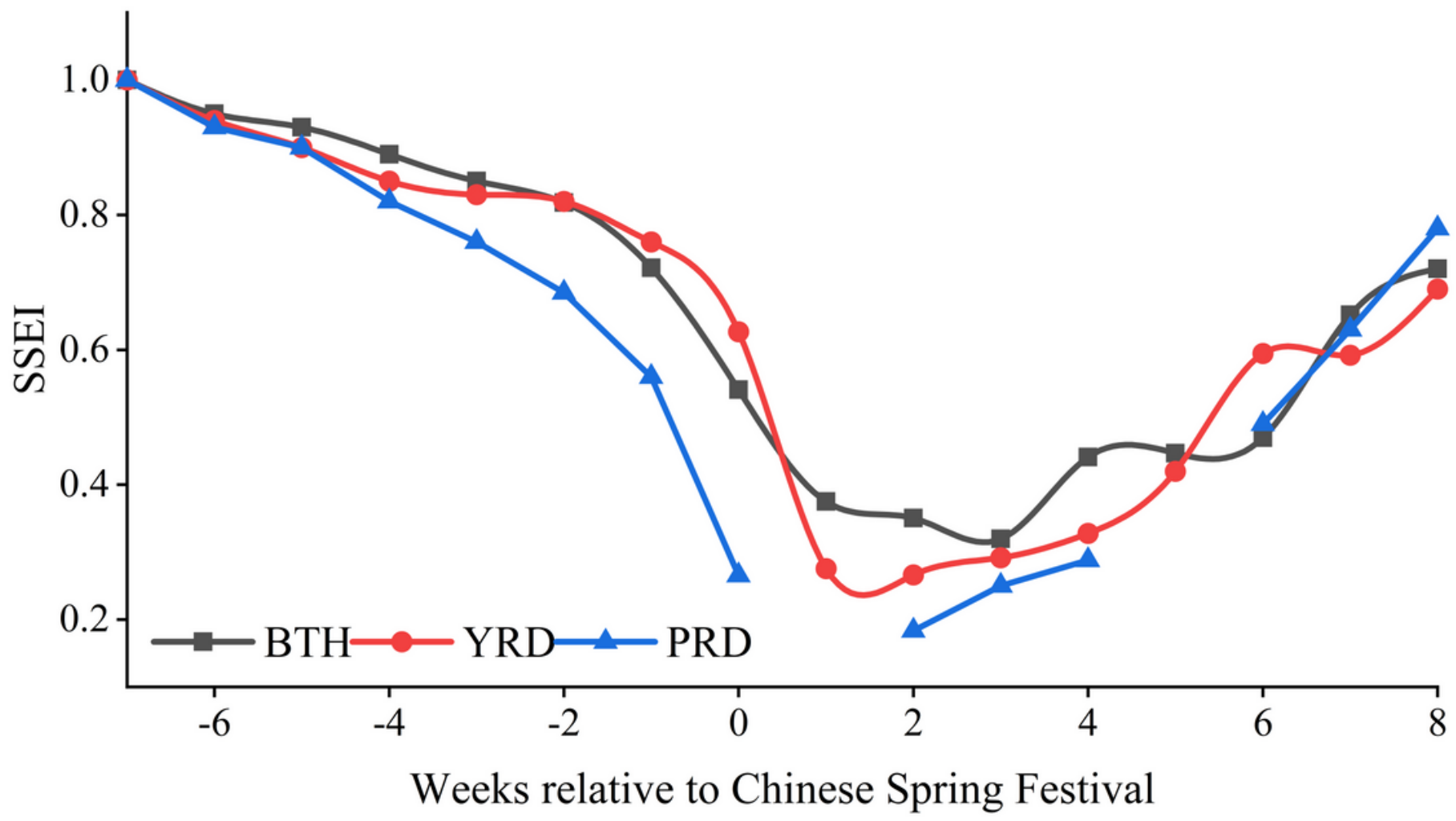

Figure 7 
Weekly variation of the SSIE of three metropolitans in China during the 2020 Chinese Spring Festival period. 